\title{
Risk Analysis for the Fire Safety of Airline Passengers
}

Richard L. Smith

Building and Fire Research Laboratory

Gaithersburg, Maryland 20899

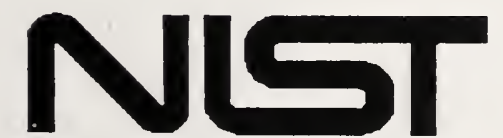

United States Department of Commerce hnology Administration ional Institute of Standards and Technology

$Q C$ 100 .456 



\section{Risk Analysis for the Fire Safety of Airline Passengers}

Richard L. Smith

\section{June 1994}

Building and Fire Research Laboratory

National Institute of Standards and Technology

Gaithersburg, MD 20899

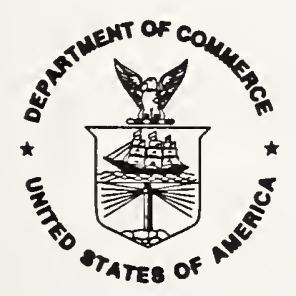

U.S. Department of Commerce

Ronald H. Brown, Secretary

Technology Administration

Mary L. Good, Under Secretary for Technology

National Institute of Standards and Technology

Arati Prabhakar, Director 



\section{Contents}

1 Introduction 1

2 Influence diagrams $\quad 5$

$\begin{array}{lll}3 & \text { Software evaluation } & 10\end{array}$

4 An Operational Example of the Working of Influence Diagrams for Risk Analysis

5 What remains to be done. 


\section{LIST OF TABLES}

2.1 Decision Analysis Software Development Matrix . . . . . . . 8

3.1 Available Software . . . . . . . . . . . . . . 10 


\section{List OF FiguRES}

2.1 Minimal Influence Diagram $\ldots \ldots \ldots$

2.2 Expanded Minimal Influence Diagram . . . . . . . . . . . 7

4.1 Water Mist . . . . . . . . . . . . . . . . 13

4.2 Fatalities . . . . . . . . . . . . . . . . . . . 14

4.3 Number Killed per Accident . . . . . . . . . . . . . . 15

4.4 Killed by Fire . . . . . . . . . . . . . . . . 16

4.5 Rate of Deplaning . . . . . . . . . . . . . . . 17

4.6 FAA Degree of Incapacitation . . . . . . . . . . . . 18

4.7 FED Due to Toxic Gases . . . . . . . . . . . . . . . . . 19

4.8 Water Mist . . . . . . . . . . . . . . . 20

4.9 Prob. of Death by Impact . . . . . . . . . . . . . . . . 21

4.10 Concentration of $\mathrm{CO} \ldots \ldots \ldots \ldots 22$

4.11 Table of Concentration of $\mathrm{CO} \ldots \ldots \ldots 22$

4.12 CO Factor . . . . . . . . . . . . . . . . . . . . 23

4.13 CO Incap . . . . . . . . . . . . . . . . . . . 24

4.14 Cumulative Probability of Total Deaths . . . . . . . . . 25

4.15 Probability Density of Total Deaths . . . . . . . . . . 26

4.16 Total Deaths Importance . . . . . . . . . . . . . . . . . 27 


\begin{abstract}
The purpose of this report is to describe the National Institute of Standards and Technology's work to date relating to the general methodology being developed for the project Risk Analysis for the Fire Safety of Airline Passengers and the software being used to facilitate this methodology. The approach selected involved the use of influence diagrams. Therefore, a brief discussion of influence diagrams is given. The status of their application to the water mist system for passenger planes is given and the overall approach to carrying out the project is described. An example is included that shows how the process works, but the case is fictional, not intended to be realistic.
\end{abstract}

Keywords: risk analysis, risk management, probability, decision analysis, artificial intelligence, fire research 


\section{INTRODUCTION}

Airline fire safety is important for airline passengers and for the potential flying public that needs to be assured of the safety of flying. The public is not just concerned with the real risk but their perception of risk[1]. Therefore, not only does the real risk have to be acceptable, but the public perception of risk to airline passengers must also be acceptable.

The Federal Aviation Administration (FAA) has the responsibility of deciding public policy issues relating to fire safety of passenger airplanes. Fire risk analysis and management for passengers is a very challenging task. What is the risk due to unwanted fires associated with passenger airplanes? What steps can be taken to reduce this risk? Do these steps introduce another larger risk? What are the costs of taking these steps? These are some of the questions that needed to be answered. Making the best decision possible relative to a particular fire safety system is clearly very important. Lives can be saved or lost, people can suffer unnecessarily because of injuries, or there can be undesirable financial consequences. Some undesirable financial consequences are:

- the direct fire losses associated with an unwanted fire,

- the cost of installing and maintaining the fire safety system, and

- the indirect costs associated with an unwanted fire such as the reduction of the number of persons flying after a major plane crash.

In fire risk analysis and management there are no correct answers, only correct procedures. There are no correct answers because the final answer of how to manage risk depends upon the value system of the decision maker. Since people have different values they can arrive at different valid answers. On the other hand, the procedure for making a proper analysis is on firmer footing because of the use of logic and the scientific method. "It is now possible to examine potential hazards 
in a rigorous, quantitative fashion and thus to give people and their representatives facts on which to base essential personal and political decisions." [1]

The purpose of this report is to describe the National Institute of Standards and Technology's work to date relating to the general methodology being developed for the project Risk Analysis for the Fire Safety of Airline Passengers and the software being used to facilitate this methodology. The objective of this project is "... to develop the generic methodology and an intelligent computer program that will compute the fire risk for passengers of airlines assuming the implementation of various fire safety regulations ${ }^{1}$." If this project is completed, this methodology will manifest itself as a computer program. This program will allow determination of the risk assuming the implementation or the removal of various fire safety systems or other changes that impact the safety of passengers of airlines. This will enable airlines or airplane manufacturers to achieve the same level of risk by different approaches. This would encourage innovation by the industry in improving safety. In making an analysis of the merit of a fire safety feature it is desirable to have the methodology for using the state-of-the-art safety analysis technology automated. This would allow the appropriate use of:

- the historical data on fire losses in airplanes,

- the results of experiments and tests,

- the predictions of physical science models, and

- experts' opinions.

It also would be of value for the program to have the ability to report the source of each piece of knowledge or assumption made that is used in a particular analysis. The system should allow various safety features to be analyzed independently or collectively. It should allow one to remove one safety feature and replace it with another. The system should allow an individual to make his/her own analysis by making his own assumptions and entering his own data. This analysis should be recorded so his inputs and conclusions would be available for future reference and review by others. Such a program would make explicit the reasoning used, the assumptions made, and the knowledge used.

\footnotetext{
${ }^{1}$ Contract with FAA Technical Center Atlantic City New Jersey. Contract number DTFA03$92-\mathrm{Z}-00018$
} 
Injuries or deaths due to airplane fires are rare events. Therefore, there is not a large body of relevant statistical data that can be used to determine the impact of various fire safety strategies. One approach to evaluating the merit of a fire safety system is to do a cost/benefit analysis based on an analysis of past accidents using classical statistical techniques. However, each crash is studied by the government so that changes can be made in procedures or equipment to reduce the likelihood of a similar accident occurring. Therefore, the historical evidence available is inappropriate for the applications of classical statistical techniques in fire risk analysis for airline passengers if significant changes are introduced to avoid accidents or for other reasons.

The risk problem for airline passenger safety is very complex and has large uncertainty in the relevant knowledge. Formal decision methods can be used to address these types of decision problems that are too large and complex to be dealt with by intuition. However, the formal decision methodology needs to make intuitive sense to the decision maker.

A rigorous risk analysis methodology for the FAA should:

- Be based on the most appropriate scientific results obtained by responsible and appropriate research practices [2] and

- Follow sound professional practice for decision analysis [3].

In particular such a methodology should require (or provide for):

- the statement of significant assumptions,

- the statement of the decision criteria,

- the sources of the scientific results used,

- the statement of uncertainties for all input and output variables,

- the performance of a systematic sensitivity and uncertainty analysis on the decision model, and

- the clear and complete documentation of the analysis. 
Recognizing the importance and the difficulty of finding a usable rigorous methodology for their analyses, the FAA started this project. Because of the lack of the methodology being developed by this project, previous analyses [4] for the FAA were forced to fall short of these requirements. Without the appropriate automated methodology it is extremely difficult to satisfy all these requirements. The methodology being developed in this project will enable the FAA to follow sound professional practice for decision analysis.

In the last decade considerable progress has been made in decision analysis and artificial intelligence in dealing with reasoning with uncertainty or vague knowledge. Some advances have used Bayesian probability theory [5], influence diagrams [6], expert systems [7], and the Maximum Entropy theory [8]. This project applies some of these advances by using influence diagrams for the risk analysis of the fire safety of airline passengers.

There are three major roles that must be filled in order to develop this methodology successfully: the decision maker, the domain expert, and the decision analyst. The methodology is developed to assist the decision maker in making a decision. Therefore, the decision maker must identify all acceptable alternatives. $\mathrm{He} / \mathrm{she}$ must identify what he values so various consequences can be ranked accordingly to their desirability based on his values. Finally, he must believe in or trust the methodology for otherwise he will not use it. In decisions relating to airline fire safety there will be relevant knowledge available only from certain scientific or technical domain experts. These domain experts, in addition to supplying their domain knowledge, must concur that the portion of the total model that covers their domain is correct. Finally, the role of the decision analyst is to construct the model in cooperation with the decision maker and domain experts.

Next is a brief discussion of the influence diagrams. This will be followed by an evaluation of the various software shells that were available initially to implement the initial version of this methodology. Then the current status of the model development for the water mist decision will be reviewed. Finally, what remains to be done to finish this project is discussed. 


\section{INFLUENCE DIAGRAMS}

After a careful study of the literature, the decision was made to use the newer influence diagram rather than the traditional decision tree. One reason for this choice was that unlike decision trees, influence diagrams grow linearly with the size of the problem, while decision trees grow much faster. In addition, influence diagrams:

- clearly and simply represent probabilistic and informational dependencies among problem variables, while decision trees do not,

- provide a demonstrable rational line of reasoning, and

- facilitate the identification of what portions of existing knowledge need improvement for the biggest improvement in the decision of interest.

Therefore, influence diagrams were selected rather than decision trees[6].

We will give here a brief review of influence diagrams. More extensive discussions can be found in the literature [6],[9].

Influence diagrams are a graphical representation of decisions where relevant variables, decisions, and consequences are represented by nodes and their relationships are indicated by arcs. Influence diagrams are a formal, mathematical, rigorous representation of a decision problem that can be solved by a computer and easily understood by people. For any particular decision problem there may be a number of influence diagrams that correspond to a particular decision. Thus, there is not a unique influence diagram for any particular decision.

The principal components of influence diagrams are nodes and arcs. The most important nodes represent:

1. Decision variables which are quantities over which the decision maker exercises direct control; 
2. Value variables which represent aspects of the preferences of the decision maker; and

3. Chance variables which are uncertain quantities that represent properties of the states of the world.

The two types of arcs are informational and conditional arcs. Informational arcs are arcs which point to a decision variable. All other arcs are conditional arcs. We will also use a submodel node which is just a logical collection of the above nodes.

In Figure 2.1 we show a minimal influence diagram. The rectangular node labeled

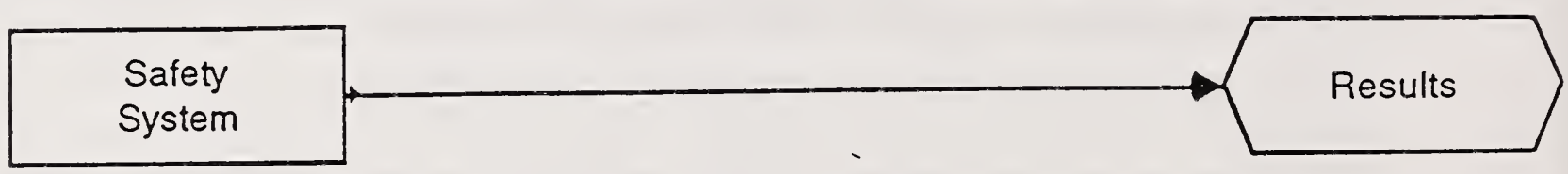

Figure 2.1: Minimal Influence Diagram

"Safety System" is a decision variable. It could correspond to the decision of whether or not to have water mist systems required on airlines or some combination of safety features. The hexagonal node represents a value variable. The arc connecting these two nodes is a conditional arc, i.e., the result depends upon the decision. If two nodes are independent there is no arc connecting them. Thus a non-conditional arc is the arc not drawn. Figure 2.2 shows the first figure expanded by two chance nodes, deaths and costs. Again all the arcs are conditional arcs.

An influence diagram can be viewed at three levels: relationship, functional, and numerical. Figure 2.2 shows the relationships between four variables. At a deeper level, the functional relationship of, say, the death node can be given and included in its description. At a still deeper level, numerical values can be assigned where appropriate, and computed elsewhere. 


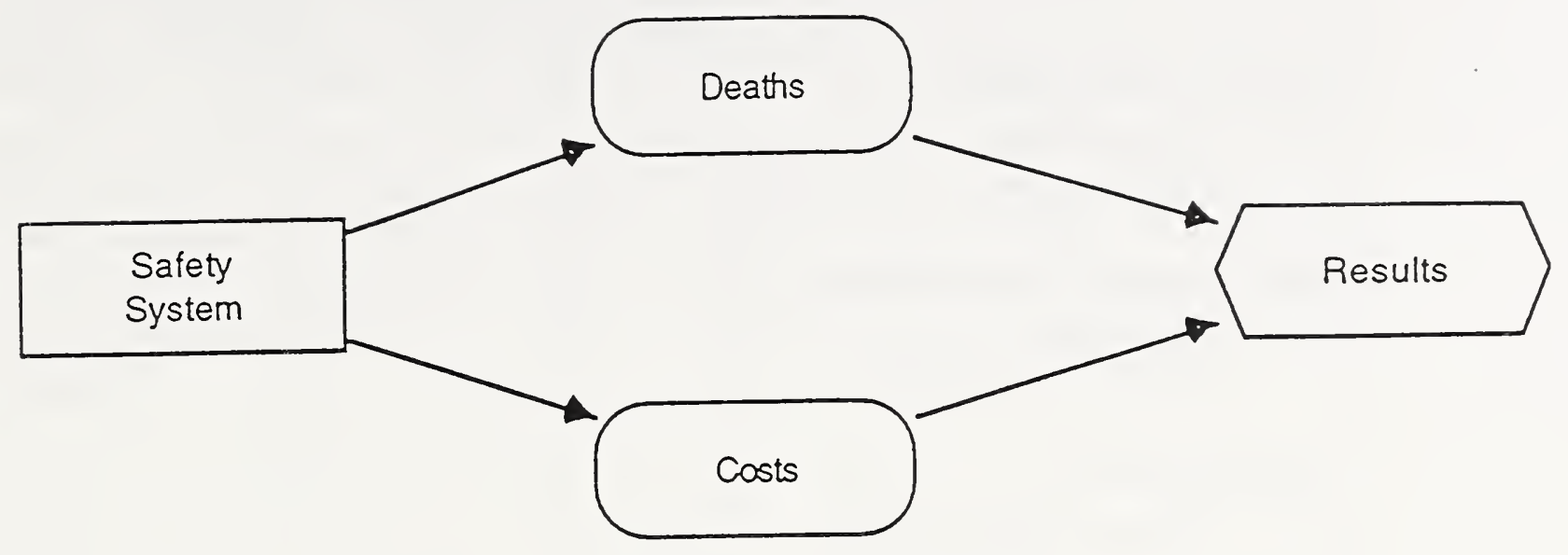

Figure 2.2: Expanded Minimal Influence Diagram

The model of the decision process described by Figure 2.2 is very simple. In general, decisions are much more complex. For example, the cost node, rather than being a chance node, could be a submodel. This submodel would include all the variables relevant to determining the cost variable. Therefore, influence diagrams can consist of many submodels. This allows the construction of a model that at the highest level can be understood by the decision maker without the confusion of all the details. It also allows specialists to determine submodels associated with their specialty without being distracted by other specialized areas or the total picture. This is an example of the divide and conquer technique of solving complex problems.

The influence diagram representation of the decision model is developed by an iterative and evolutionary process as depicted in table 2.1 [11]. The first model developed is the pilot model which is an extremely simplified representation of the problem, useful only for determining the most important relationships. When we reach the sixth step, see table 2.1, we start over again with the first step for the pilot model or move on to the prototype model. The prototype model is a quite detailed representation of the problem that may, however, still be lacking a few important attributes. It does demonstrate how the final version will appear and perform. Again when we reach the sixth step we start over again or move on to the production model. This model is the most accurate representation of reality 


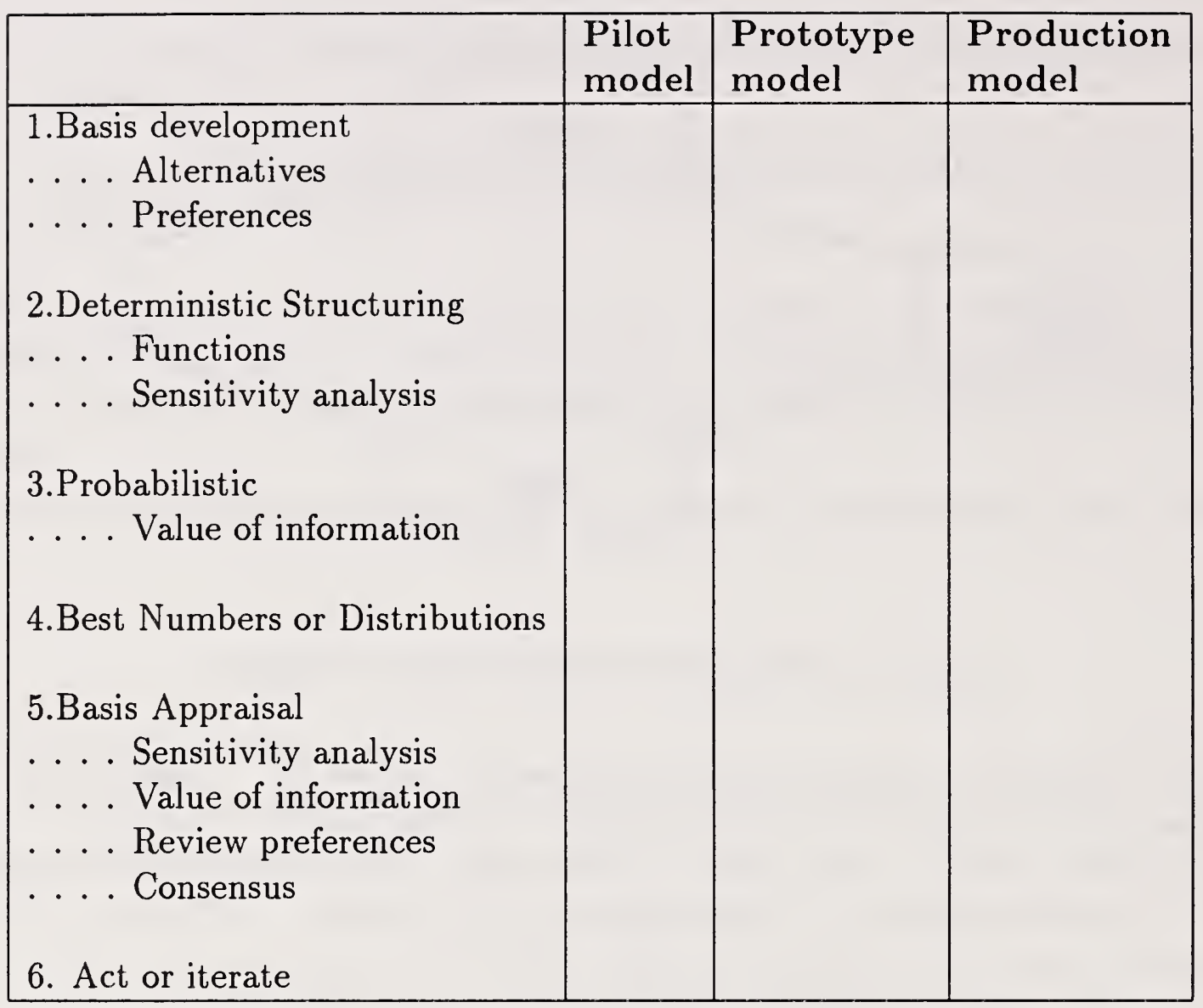

Table 2.1: Decision Analysis Software Development Matrix

that decision analysis can produce.

For each of these risk models the first step is to do the basic development which includes determining the decision maker's alternatives and preferences. The second major step consists of developing the deterministic structures of the model. This includes writing explicit functional relationships that describe this relationship. Then a sensitivity analysis is performed to identify variables that have very little influence and those which have an overwhelming influence. The variables that have very little influence can be eliminated from the model to simplify it. On the other hand, the variables that have an overwhelming influence are candidates for subdivision into more variables. The third step is the probabilistic evaluation which includes the use of probability distributions instead of unique values. This step is where the uncertainty of our knowledge first enters. Therefore, we eval- 
uate the value of reducing the uncertainty in the various variables to determine the effect of doing so on our results. This can potentially identify needed areas of research. The fourth step consists of finding and utilizing the best numerical values and distributions for the variables in the model. For the fifth step, the basic appraisal, the sensitivity analysis and value of information analysis are repeated, a review of the decision maker's preferences is made, and the existence of a consensus on the model is verified. At this point the model is either complete or the development process is started over and iterated until the decision maker is satisfied. 


\section{Software evaluation}

Buying good software is almost always cheaper than developing it. Therefore, a search for software to be used to construct decision models was made after deciding to use influence diagrams. The main features the software was to possess were the capability to:

1. be used to construct influence diagrams,

2. operate on either an IBM-compatible PC or a Macintosh,

3. compute the influence diagram in a predictive mode,

4. provide for extensive node definition and description,

5. allow probability distributions as definitions of values, and

6. be user-friendly for the construction and editing of influence diagrams.

In addition, the algorithm used should be verifiable and the source code for the program must be available.

The software candidates that were identified are given in Table 3.1.

\begin{tabular}{|l|l|l|l|}
\hline Software & Platform & Applications & Company \\
\hline Demos & Mac & predictive & Lumina \\
KI DX & Mac, PC & diagnosis & Knowledge Ind. \\
Ergo & Mac & diagnosis & Noetic Systems \\
HUGIN & PC, Unix & predictive, diagnosis & Hugin Expert A/S \\
IDEAL & Unix,Mac & research & Rockwell Science \\
\hline
\end{tabular}

Table 3.1: Available Software 
Because the software is for risk assessment, it must be capable of running predictive applications. The only ones that will clearly do this are Demos, Hugin, and IDEAL. Demos was the only one available commercially at the start of this project and the only one that would run on an IBM-compatible PC or a Macintosh. Hugin only recently became available for a PC. Previously, it would only work on a Sun computer. IDEAL is available free for federal government agencies. The major drawback to IDEAL is that it requires a UNIX machine such as a Sun computer, Lisp, and Clim to run the most user-friendly version. While IDEAL may be more powerful and versatile, it would require a great deal more of an effort to use. Demos on the other hand was commercially available, albeit in a beta version, it has a user-friendly interface, and would run on a Macintosh.

The beta version of Demos (version 2.5b2) is described by Lumina's sale literature as "... a Macintosh-based, graphical environment for creating, analyzing, and communicating probabilistic models for risk and policy analysis." It can crudely be described as a graphical editor for influence diagrams and a Monte Carlo simulator. In fact it has a number of features that make the creation of influence diagrams convenient. It has the feature that uncertainty for any variable can be expressed as a probability distribution. This distribution can either be a standard distribution - such as uniform, normal, or lognormal - or it can be a discrete or continuous distribution created by the user. Uncertainties are propagated through the model to generate the corresponding uncertainties in the outputs.

In addition, Demos lets you create a hierarchy of models. This allows one to organize a large model into many manageable submodels. Each submodel is displayed in its own window.

The simulation calculation is made using Latin hypercube sampling, which is a variant of Monte Carlo simulation.

While Demos does not meet all the desired requirements, it should enable a user to at least come close to following a rigorous risk analysis methodology. It's price is about $\$ 1000$. In the future, there may be a need to select different software or to write a special software for the FAA. 


\section{An Operational Example of the Working of INFLUENCE Diagrams FOR RISK ANALYSIS}

Working an example will help the reader understand the power of the influence diagram approach to risk analysis. Working with the designated decision maker we completed the first step of the development matrix and were developing the deterministic structuring of the pilot model when worked stopped. Because the decision model is far from being completed no results displayed in this report relative to the effectiveness of a water mist system should be taken as rigorously supportable. In fact, the model at this stage of development may produce totally inaccurate results.

For this case, we chose the installation of a water mist fire suppression system on passenger airplanes[10]. This system has served as the test bed for the development of this project.

We are reporting on the pilot version (step 2: Deterministic Structuring) of the risk model. A pilot model is an extremely simplified representation of the problem. Its main use is for determining the most important relationships. For this version the only decision is whether or not to add a water mist system to the airplane and the only preference variable is the number of deaths. The model determines the expected number of deaths with and without the water mist system. The model uses a subset of FAA's incapacitation model which addresses the effects of temperature, carbon monoxide, carbon dioxide, oxygen depletion, and hydrogen cyanide.

Figures 4.1 thru 4.7 show various submodels of the FAA risk program. Figure 4.1 is at the highest level of the model. It shows one value node (Cost of Saving a Life) and four submodel nodes. It shows that the nodes Costs and Fatalities are the only nodes relevant to the Cost of Saving a Life node. The Fatalities node 


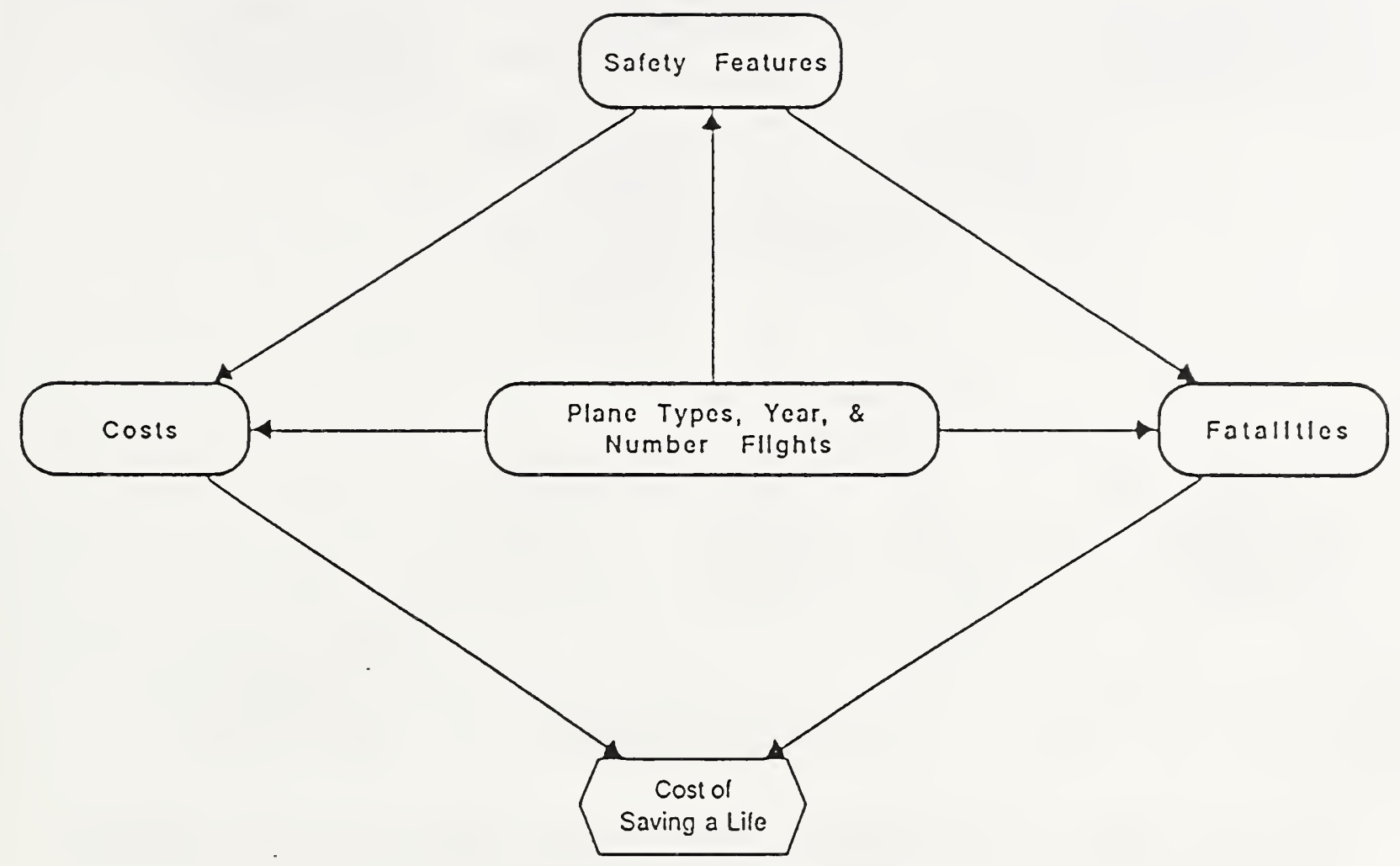

Figure 4.1: Water Mist

depends only on the two nodes:

1. Safety Features and

2. Plane Types, Years, \& Number Flights.

It is important to recognize that the lack of an arc is also significant, since it implies the independence of nodes.

What is in the submodel Fatalities is shown in Figure 4.2. The nodes with rounded corners and heavy dark lines for their border are submodel nodes. The rounded corners light line nodes are chance nodes. Thus in Figure 4.2 we see chance nodes as well submodel nodes. A node whose title is in italics (Number of Flights per 


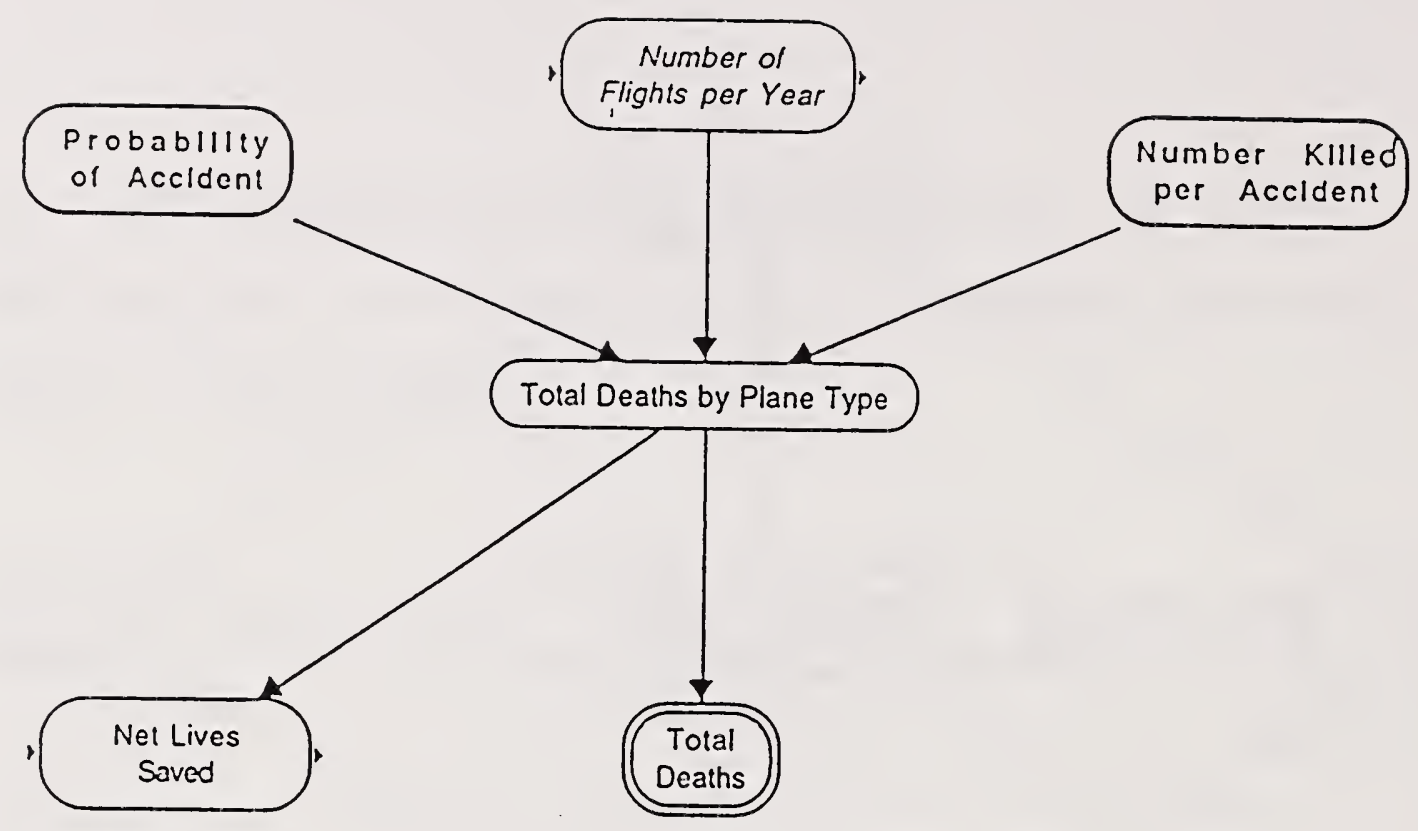

Figure 4.2: Fatalities

year) is a ghost of a node that is actually located elsewhere, but is displayed for informational purposes. The marks to the left and to the right of this ghost node indicates at least one arc pointing to and at least one arc pointing away from this node. Nodes with double-lined borders like the Total Deaths node are deterministic nodes. The relevant nodes to the node Total Deaths by Plane Type are the nodes Probability of Accident, Number of Flights per Year, and Number Killed per Accident. The Probability of Accident node is the probability of an accident per flight. This point of view looks at the accidents per flight. Another equally valid point of view is looking at the probability of an accident per hour of flight. This last point of view would result in a different influence diagram than the existing one.

Figure 4.3 shows the content of the submodel Number Killed per Accident. In this submodel there are a number of chance nodes and a submodel, Killed by Fire. We can go deeper into the model by looking into the submodel Killed by Fire which is shown in Figure 4.4. Figure 4.5 shows the content of the submodel Rate of Deplaning. The chance nodes in the upper right hand corner of the figure that 


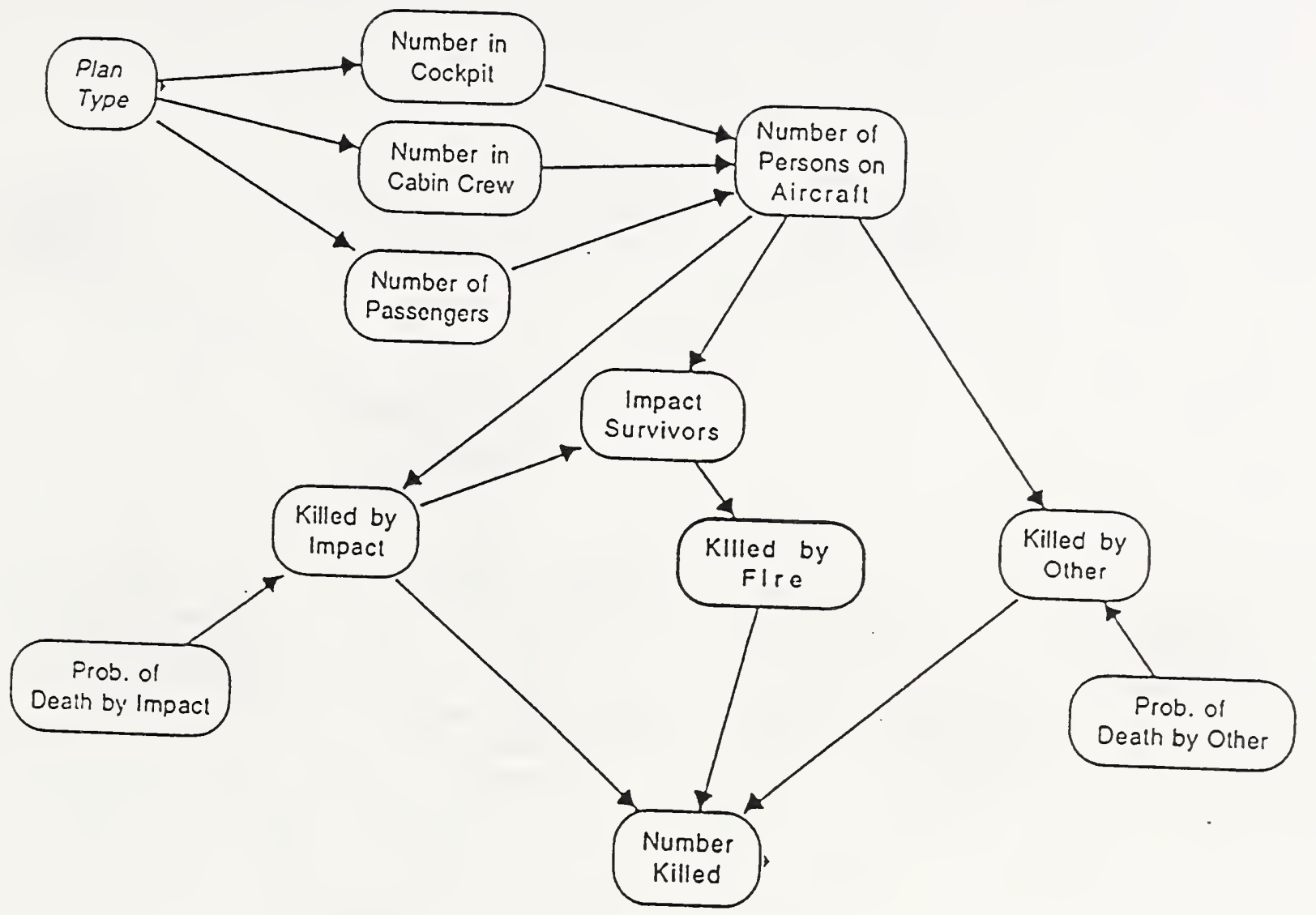

Figure 4.3: Number Killed per Accident

are partially crosshatched are nodes that could be added to the model at a later date, but are not in the model now. Still deeper into the model we see in Figure 4.6 the contents of the submodel FAA Degree of Incapacitation. Figure 4.7 shows the contents of the submodel $F E D^{1}$ Due to Toxic Gases.

We now want to turn to describing what information is contained within the nonsubmodel nodes. Figures 4.8 thru 4.13 are examples of what is stored in nodes. Figure 4.8 shows the Decision node Water Mist. We see a common format of information. On the top line we see the designation as to what type of node we

${ }^{1}$ Fractional Effective Dose (FED) 


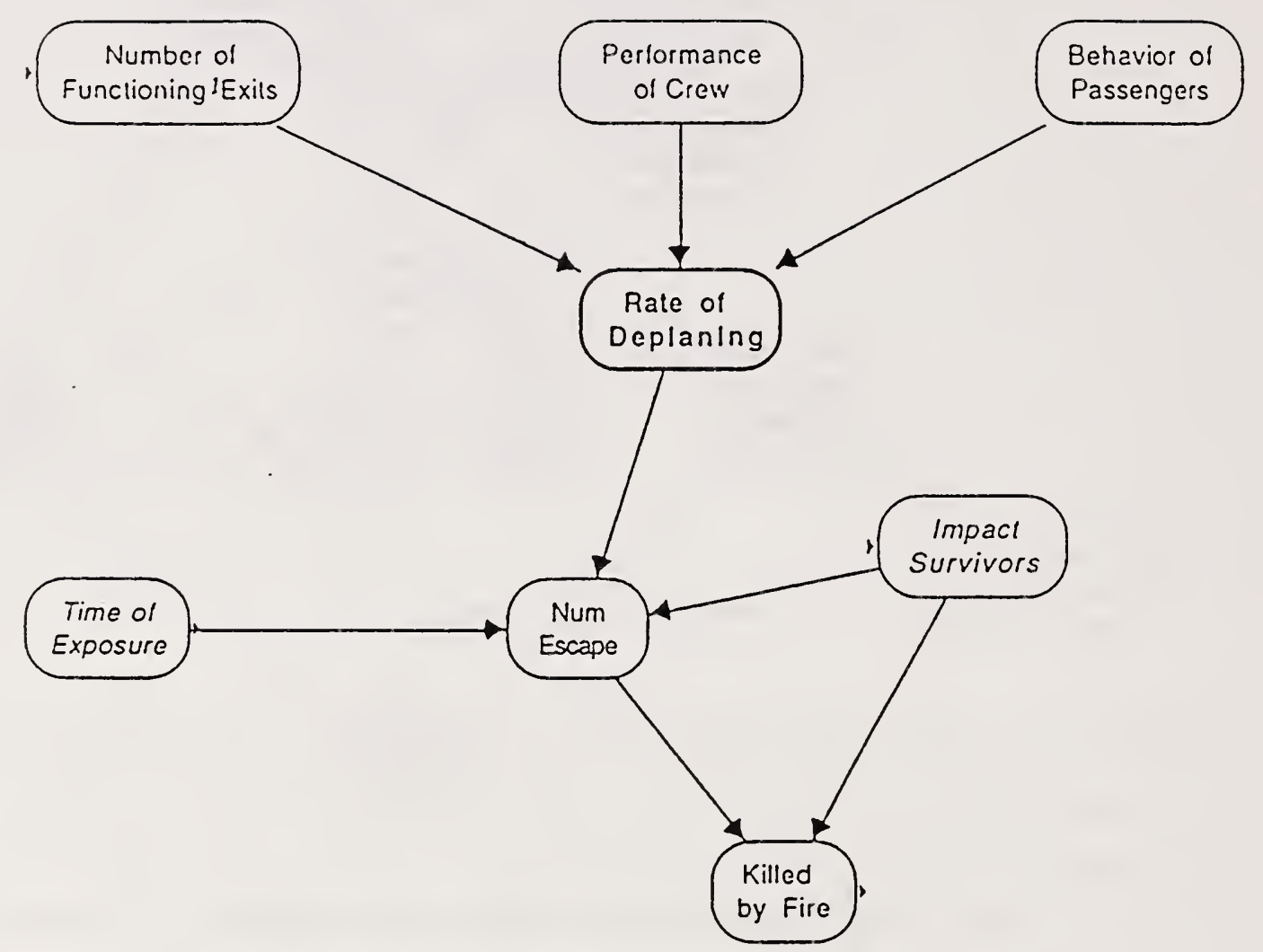

Figure 4.4: Killed by Fire 


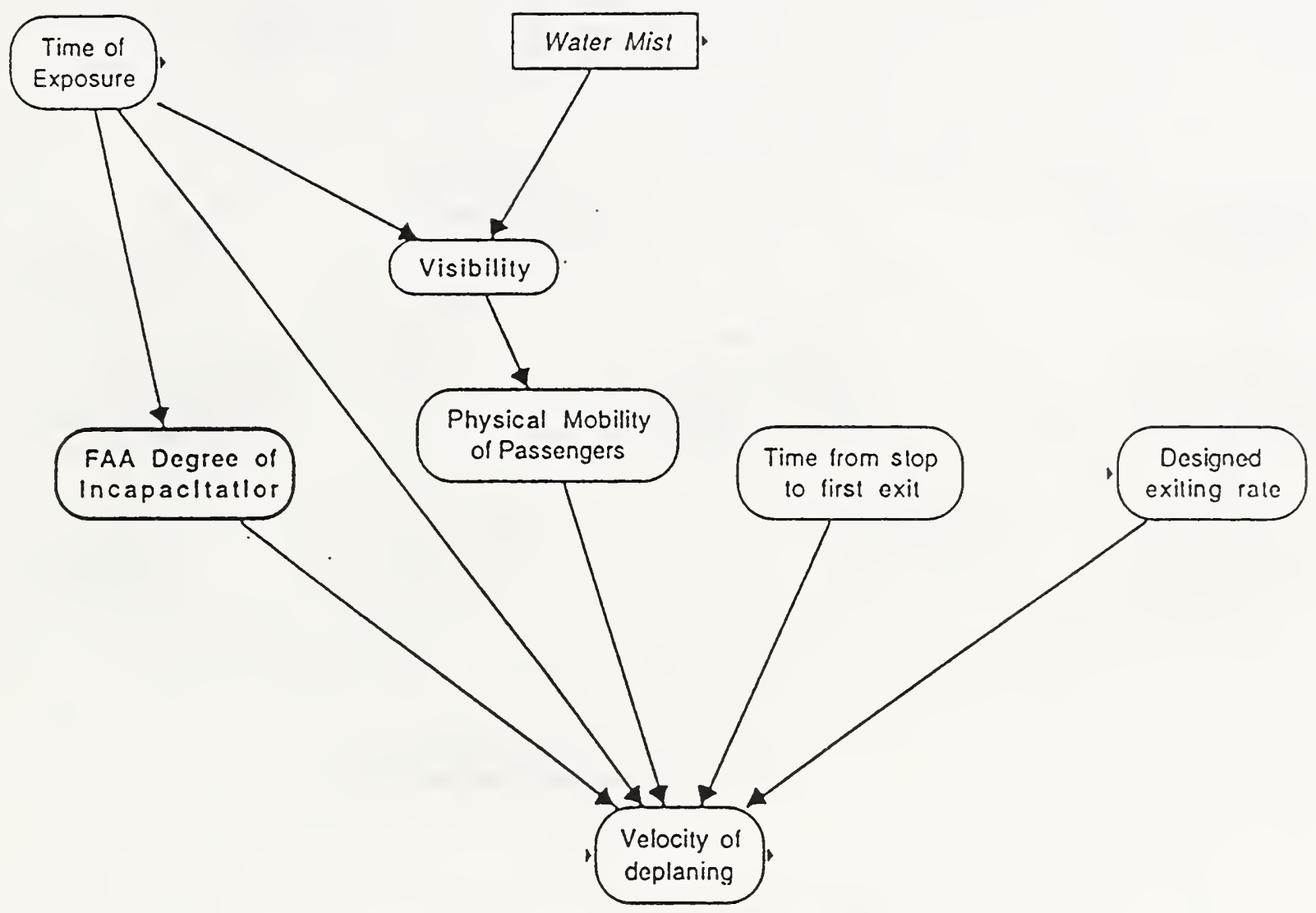

Figure 4.5: Rate of Deplaning 


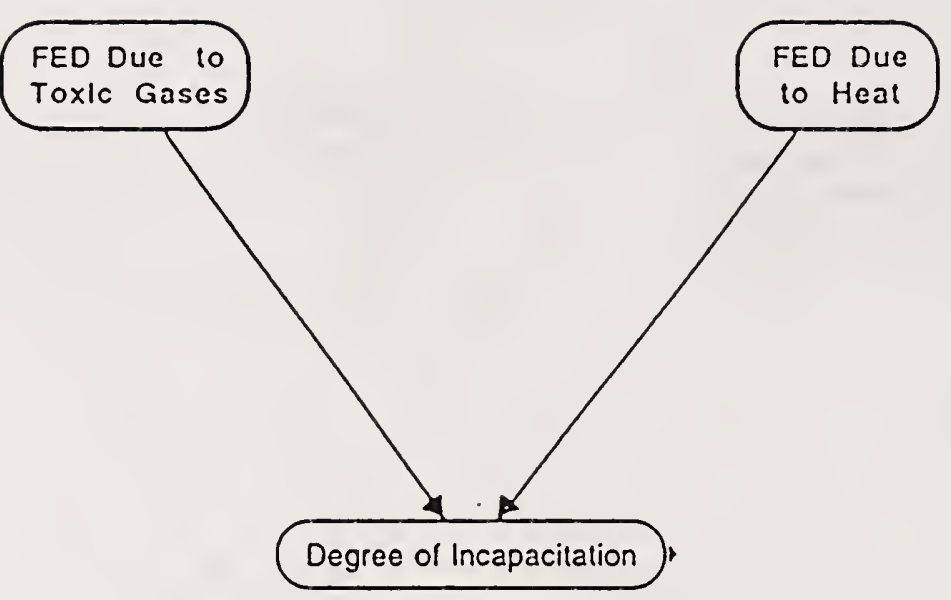

Figure 4.6: FAA Degree of Incapacitation 


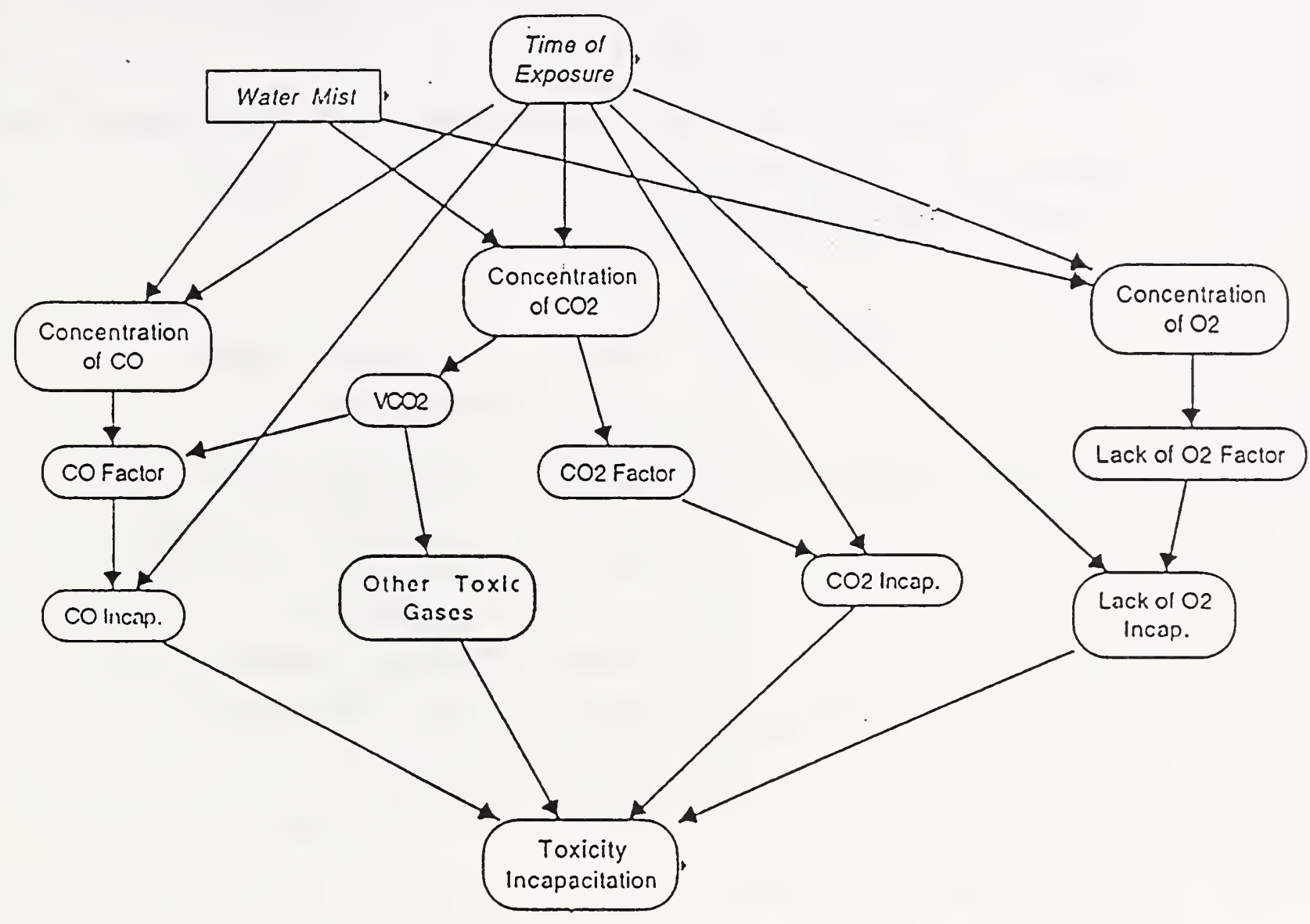

Figure 4.7: FED Due to Toxic Gases 
$\square$ Decision Water_mist1 Units:

Title: Water Mist

Description: 0 means no water mist, 1 means there is a water mist system.

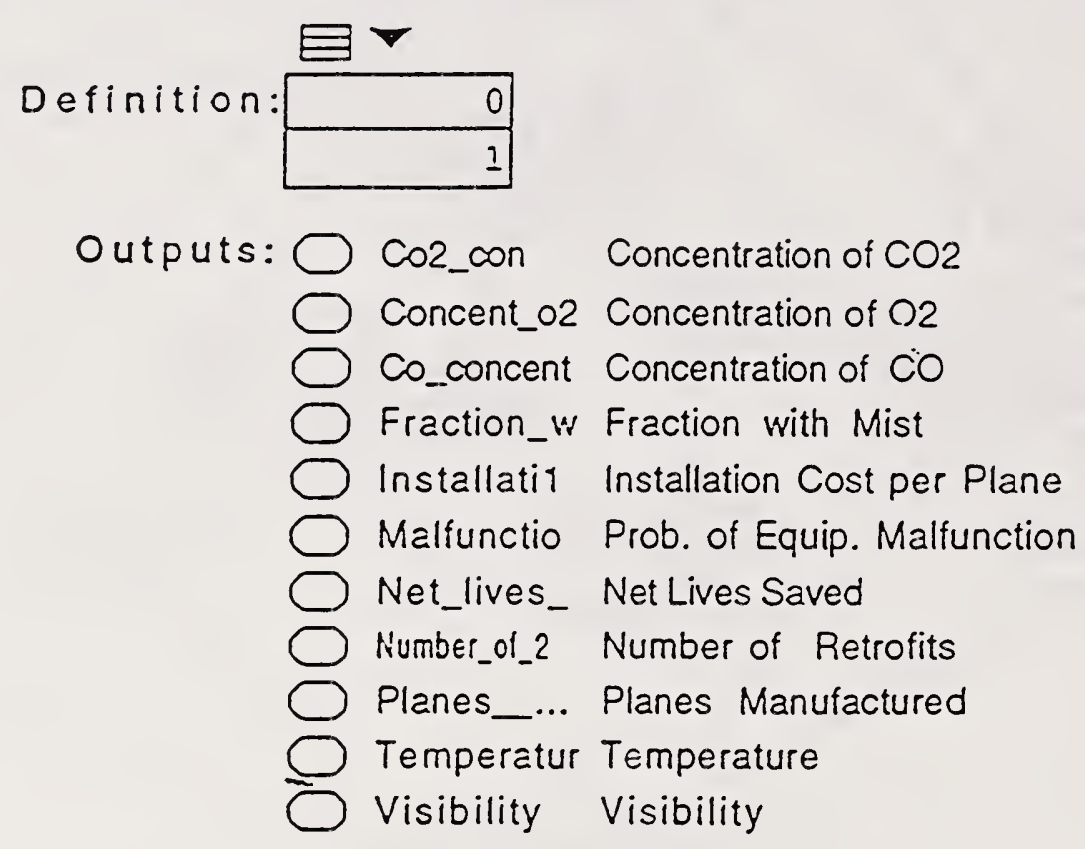

Figure 4.8: Wiater Mist 
have. This is followed by the variable name used by the computer. In this case it is Water_mist1. Finally, there is a place to enter the units of the variable. On the next line is the Title of the node which appears inside the node. Under the Title is space to type in a short description of the node. Below the Description is where the functional definition of the node is given. For the water mist variable we have defined it to be either zero or one, i.e., no water mist system or a water mist system. Finally, the Outputs list contains all the variables in the full model that are explicitly dependent upon this node.

One has great flexibility in defining the relationship between nodes. For example, Figure 4.9 shows the contents of a chance node Prob. of Death by Impact for

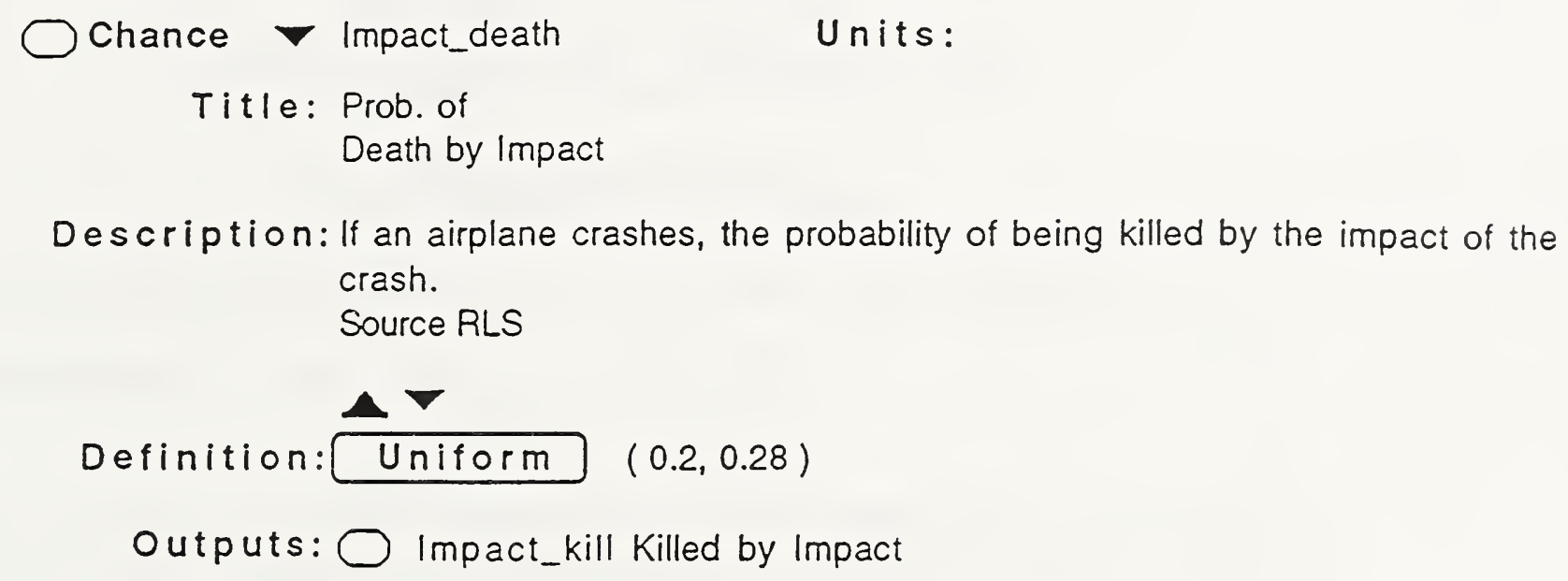

Figure 4.9: Prob. of Death by Impact

which the "definition" is a uniform probability distribution over the range 0.2 to 0.28 (arbitrarily chosen here in order to work the example). A number of other frequently used distributions can be used plus a custom distribution can be used. Figure 4.10 shows a chance node Concentration of $C O$ which is defined by use of a table of values. Figure 4.11 shows this Table of Concentration of CO. Figure 4.12 shows the content of the chance node CO Factor for which the definition is an If ... then ... else statement. This statement is from the FAA incapacitation model and it says "If the concentration of $\mathrm{CO}$ times the factor $V c o 2$ is greater than 0.01 , then return the value of the concentration of $\mathrm{CO}$ times the factor $V c o 2$ 


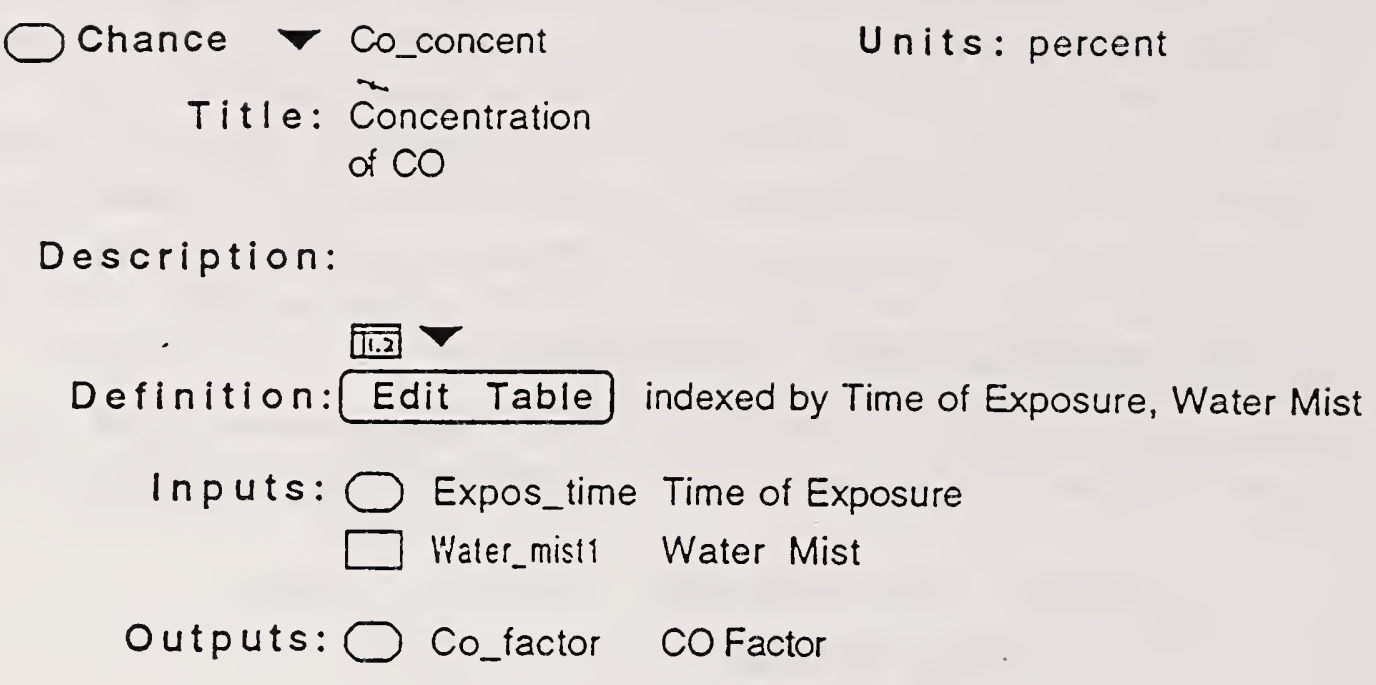

Figure 4.10: Concentration of CO

Edit Table - Concentration of co

\begin{tabular}{|c|c|c|}
\hline \multicolumn{3}{|c|}{ Time of Exposure (minutes) } \\
\hline$\nabla$ & Water Mis & \\
\hline & 0 & 1 \\
\hline 0 & 0 & 0 \\
\hline 0.5 & 0 & 0 \\
\hline 1 & 0 & 0 \\
\hline 1.5 & 0 & 0 \\
\hline 2 & 0.08 & 0.07 \\
\hline 2.5 & 0.23 & 0.21 \\
\hline 3 & 0.38 & 0.22 \\
\hline 3.5 & 0.62 & 0.32 \\
\hline 4 & 0.78 & 0.33 \\
\hline
\end{tabular}

Figure 4.11: Table of Concentration of $\mathrm{CO}$ 


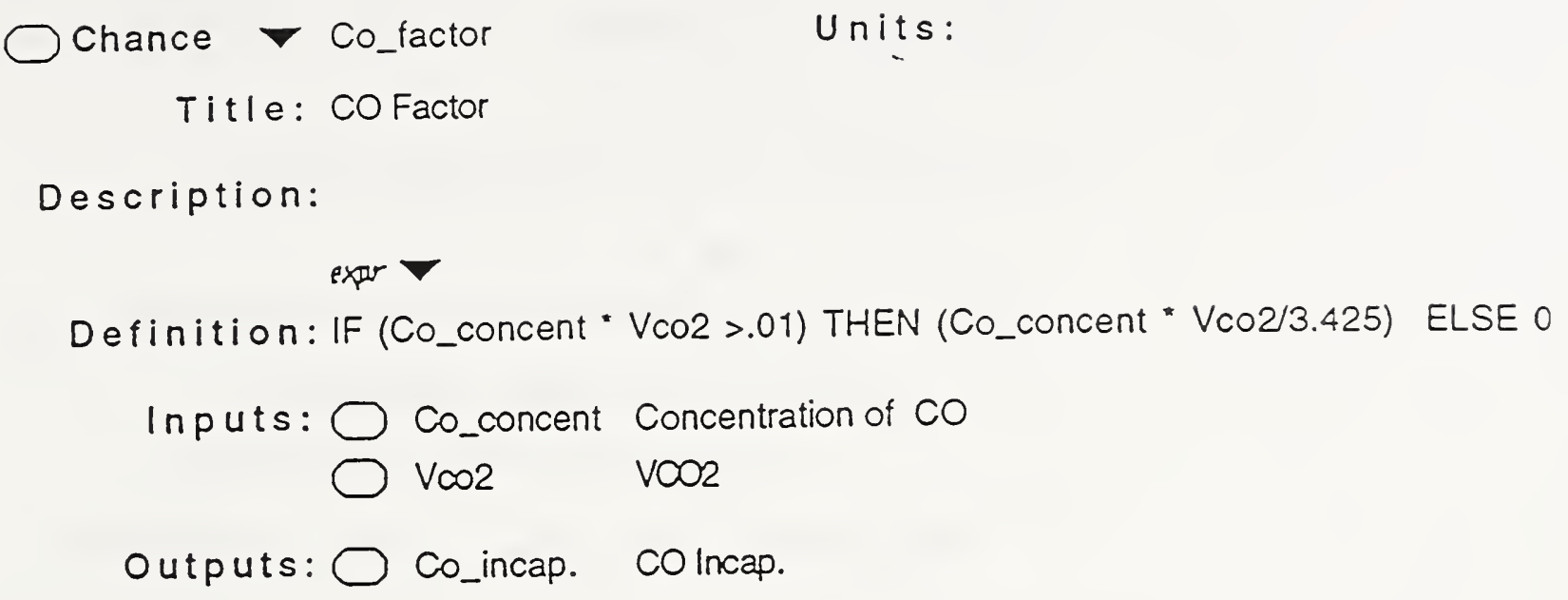

Figure 4.12: CO Factor

divided by 3.425 ; otherwise return zero. The factor $V c o 2$ is defined as

$$
V \operatorname{co} 2=\frac{e^{.2496 * C+1.9086}}{6.8}
$$

where $C$ is the concentration of carbon dioxide. Figure 4.13 shows the definition of the chance node $C O$ Incap and an integration of the variable CO Factor over Time of Exposure. There are other possible relationships, but they are too numerous to try to include them all.

Demos provides for a number of ways of displaying the results of the computer analysis. Figures 4.14 and 4.15 show two examples of how the results can be displayed. Figure 4.14 shows the Cumulative Probability of Total Deaths with the water mist system and without it. The interpretation of this figure may be helped by realizing that if no one was ever killed, the cumulative probability curve would have a constant value of one for all values of total deaths. The solid curve, which corresponds to the results without the water mist system, is below the dashed curve, which corresponds to the results with the water mist system. Since for any value of constant cumulative probability the value for total deaths is higher, this figure indicates the water mist system is safer. However, we must repeat the caution that these results may not be correct. In Figure 4.15 is shown the Probability Density of Total Deaths with and without the water mist system. 


Chance $\nabla$ Co_incap.
Title: COIncap.
Description: The FED due to carbon monoxide
Definition:
InTtEGRATE (Co_factor, Expos_time)
\[ \text { Co_factor COFactor } \]
Outputs:

Figure 4.13: CO Incap

Again we see that values of total deaths are greater for the non-water mist case than with the water mist case. We repeat our caution that these results are not based on a thorough analysis and therefore may be misleading.

While the project has not completed step 2 of the Pilot model, we felt it would be of interest to see a capability of Demos to do value of information analysis. Therefore, we introduced probability distributions for six arbitrary variables. Figure 4.16 shows a graph of the relative importance of these six chance variables in determining the value of the Total Deaths node. We see that the variable on the far left is the most important while the one on the far right of the two sets is the least important. Therefore, an investment in improving the variable on the left would have the biggest payoff. 
Year $\leadsto 1994$

Key: Water Mist

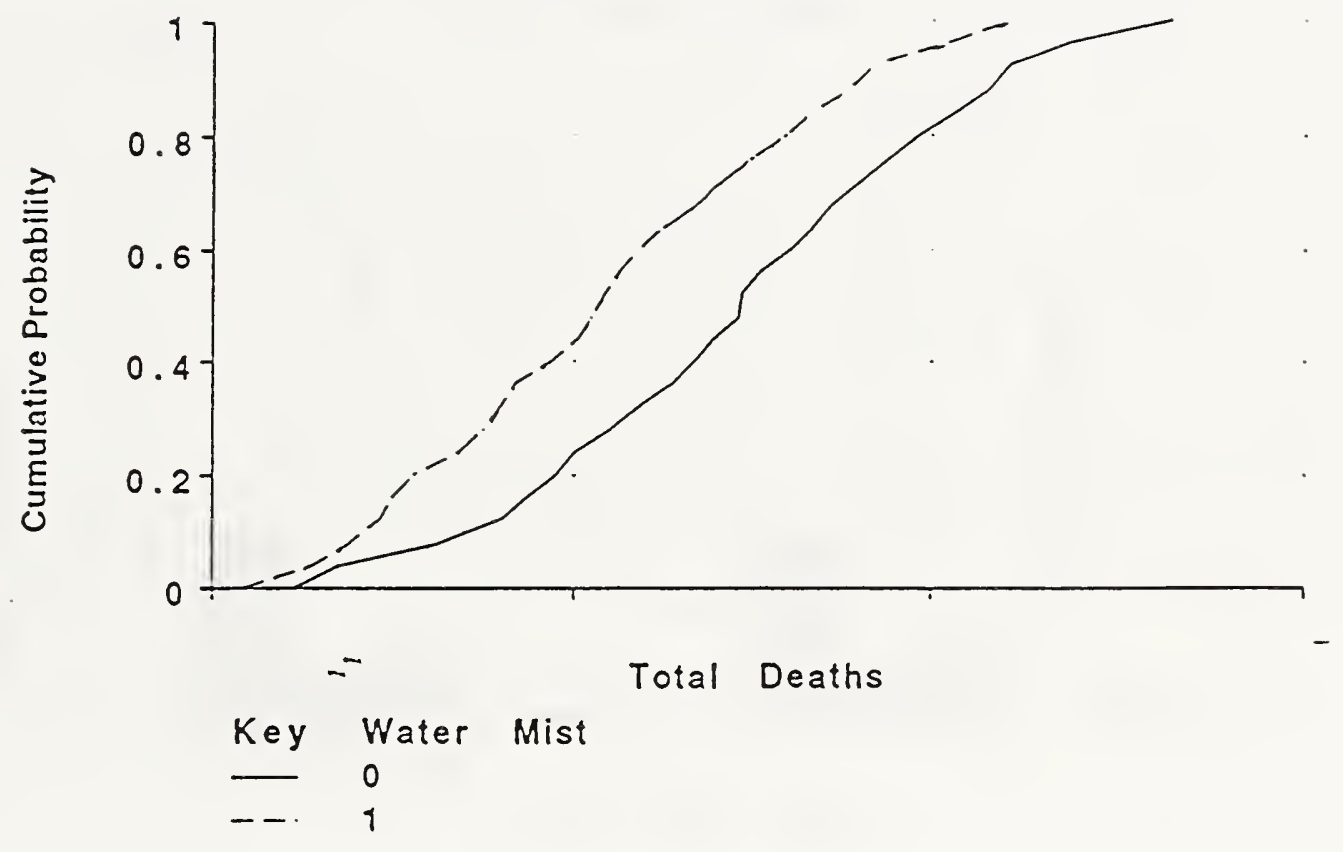

Figure 4.14: Cumulative Probability of Total Deaths 
Year $\Rightarrow 1994$

Key: Water Mist

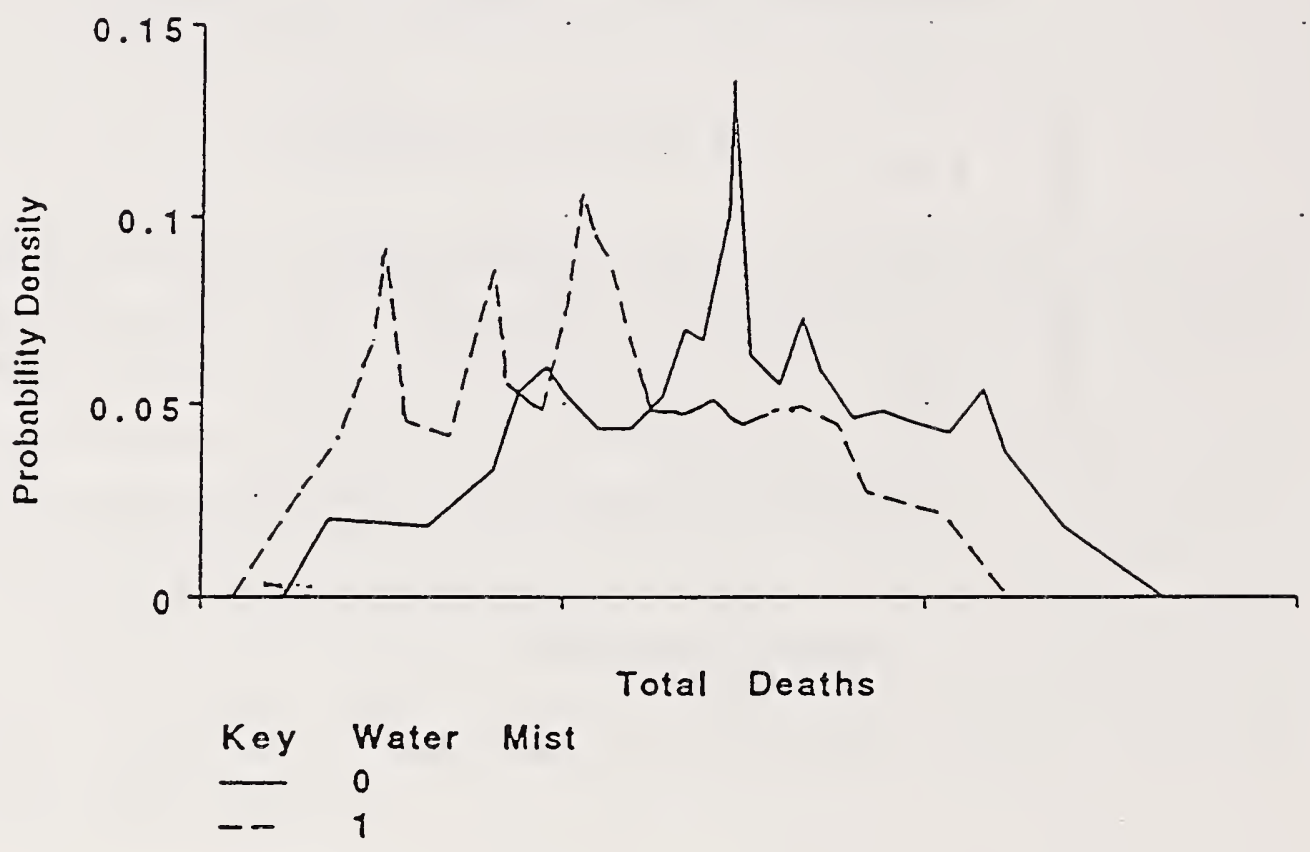

Figure 4.15: Probability Density of Total Deaths 

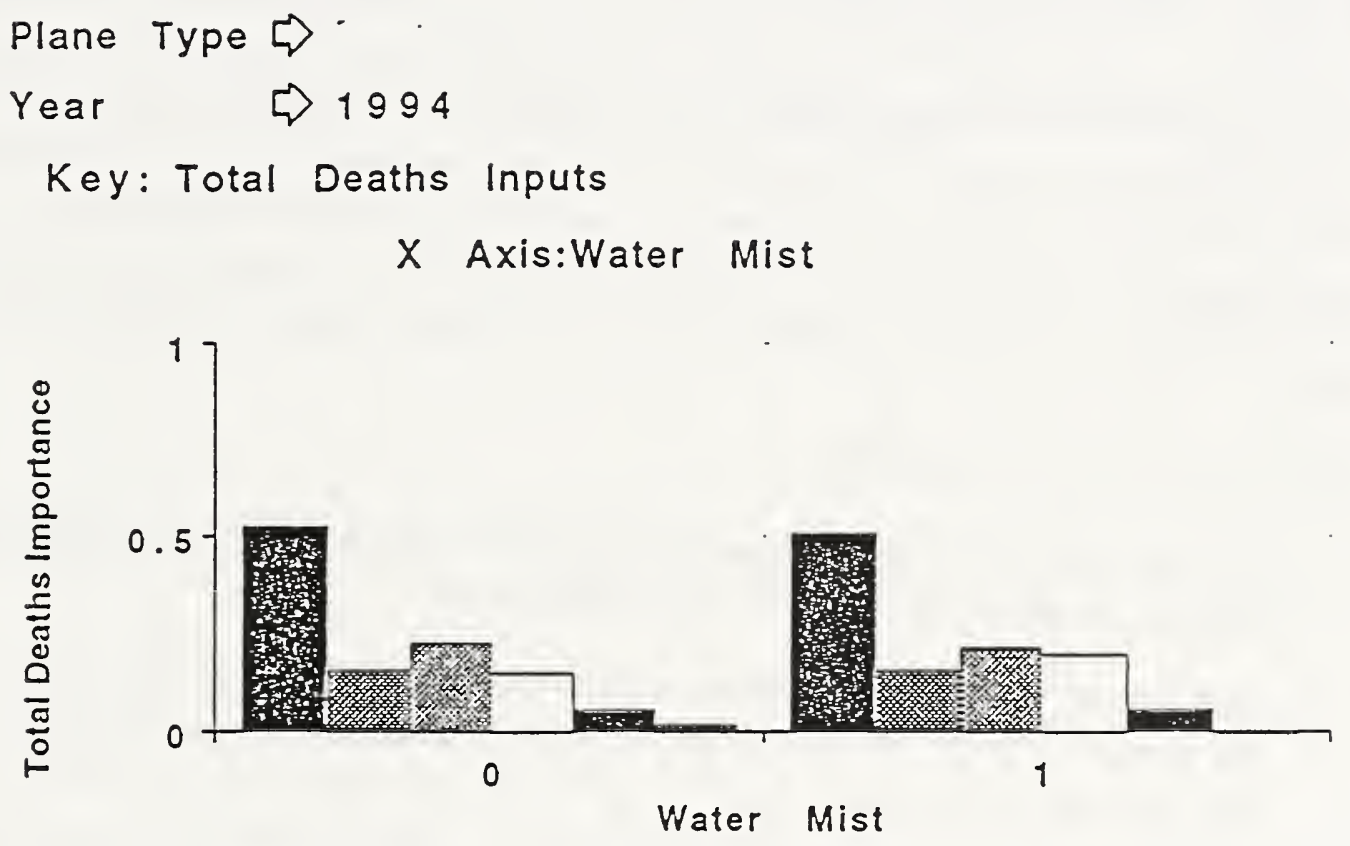

Figure 4.16: Total Deaths Importance 


\section{What REMAins TO BE DONE.}

Where we stopped work in table 2.1 tells most of the story of what remains to be done. As has been pointed out, the influence diagram representation of the decision model is developed by an iterative and evolutionary process as depicted in table 2.1. Since work was stopped during the second step in developing the pilot model, the work on the pilot model needs to be finished as well as the work on the other two models. For this and the other models it is critical that we work with the decision maker or someone that accurately reflects his point of view. If the designated decision maker is changed, the work on the model to date will have to be revised as needed to comply with the decision maker's point of view and values.

For each of three risk models:

1. The first step is to do the basic development which includes determining the decision maker's alternatives and preferences.

2. The second major step consists of developing the deterministic structures of the model. This includes writing an explicit functional relationship that describes this relationship. Then a sensitivity analysis is performed to identify variables that have very little influence and those that have an overwhelming influence. The variables that have very little influence can be eliminated from the model to simplify it. On the other hand, the variables that have an overwhelming influence are candidates for subdivision into more variables.

3. The third step is the probabilistic evaluation which includes the use of probability distributions instead of unique values. At this step is where the uncertainty of our knowledge first enters. Therefore, we determine the impact of reducing the uncertainty in the various parameters on the results.

4. The fourth step consists of finding and utilizing the best numerical values and distributions for the variables in the model. 
5. For the fifth step, the basic appraisal, the sensitivity analysis and value of information analysis are repeated, a review of the decision maker's preferences is made, and the existence of a consensus on the model is verified.

6. At this point the model is either complete or the development process is started over and iterated until the decision maker is satisfied.

When we reach the sixth step we start over again with the first step for the model or move on to the next model if there is one. At this stage it would be useful to introduce the model to the airline and airplane industries by convening a meeting where anyone interested could comment on the model and the plans for the next model.

Finally, we must continue the evaluation of implementation software, such as Demos. 


\section{BIBLIOGRAPHY}

[1] Morgan, M., Risk Analysis and Management, Scientific American, July 1993, pp. $32-41$

[2] Responsible Science: Ensuring the Integrity of the Research Process, Volume 1, National Academy of Sciences, National Academy of Engineering, and Institute of Medicine, National Academy Press, Washington DC, 1992

[3] Morgan, M. and M. Henrion, Uncertainty: A Guide to Dealing with Uncertainty in Quantitative Risk and Policy Analysis, Cambridge Univ. Press, 1990

[4] Speitel, L. and R. Hill, Study of Benefits of Passenger Protective Breathing Equipment From Analysis of Past Accidents, DOT/FAA/CT-88/03, 1988, National Technical Information Service, Springfield, VA 22161

[5] Pearl, J., Probabilistic Reasoning in Intelligent Systems: Networks of Plausible Inference, Morgan Kaufmann Publishers, San Matio, CA, 1988

[6] Holtzman, Samuel, Intelligent Decision Systems, Addison-Wesley Publishing Co.,Inc. 1989

[7] Henrion, M., J. S. Breese, and E. J. Horvitz, Decision Analysis and Expert Systems, AI Magazine, Winter 1991, pp. 64-91

[8] Loredo, T. J., From Laplace to Supernova SN1987A: Bayesian Inference in Astrophysics in Maximum Entropy and Bayesian Methods, P. F. Fougere, Editor, Kluwer Academic Publishers, 1990

[9] Howard, R. A., Influence Diagrams, in The Principles and Applications of Decision Analysis, Vol. 2 editors R. Howard and J. Matheson 1989 
[10] Hill, R. G., C. P. Sarkos, and T. R. Marker, Development of a Benefit Analysis for an Onboard Aircraft Cabin Water Spray System, Fire Hazard and Fire Risk Assessment, ASTM STP 1150. M. M. Hirschler, Ed., American Society for Testing and Materials, Philadelphia, 1992, pp. 116-127

[11] Howard, R. A., The Evolution of Decision Analysis in The Principles and Applications of Decision Analysis, Vol. 1 editors R. Howard and J. Matheson 1989 



\section{MANUSCRIPT REVIEW AND APPROVAL}

INSTRUCTIONS: ATTACH ORIGINAL OF THIS FORM TO ONE (1) COPY OF MANUSCRIPT AND SEND TO THE SECRETARY, APPROPRIATE EDITORIAL REVIEW BOARD

TITLE AND SUBTITLE (CITE IN FULL)

Risk Analysis for the Fire Safety of Airline Passengers

\begin{tabular}{|l|l|}
\hline CONTRACT OR GRANT NUMBER & TYPE OF REPORT AND/OR PERIOD COVERED \\
DTFA03-92-Z-00018 & \\
\hline
\end{tabular}

AUTHOR(S) (LAST NAME, FIRST INITLAL, SECOND INITIAL)

Smith, Richard L.

LABORATORY AND DIVISION NAMES (FIRST NIST AUTHOR ONLY)

Building and Fire Research Laboratory (865)

SPONSORING ORGANIZATION NAME AND COMPLETE ADDRESS (STREET, CITY, STATE, ZIP)

Department of Transportation, FAA Technical Center

Contracts Branch, ACM-510-E

Atlantic City Int'l Airport, NJ 08405

\section{PROPOSED FOR NIST PUBLICATION}

\section{JOURNAL OF RESEARCH (NIST JRES)}

J. PHYS. \& CHEM. REF. DATA (JPCRD)

HANDBOOK (NIST HB)

SPECLAL PUBLLATION (NIST SP)

TECHNHCAL NOTE (NIST TN)

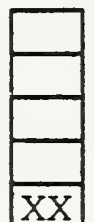

MONOGRAPH (NIST MN)

NATL. STD. REF. DATA SERIES (NIST NSRDS) FEDERAL INF. PROCESS. STDS. (NIST FIPS)

LIST OF PUBLICATIONS (NIST LP)

NIST INTERAGENCYINTERNAL REPORT (NISTIR)

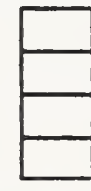

LETTER CIRCULAR

BUILDING SCIENCE SERIES PRODUCT STANDARDS

OTHER

PROPOSED FOR NON-NIST PUBLICATION (CITE FULLY)

U.S.

\begin{tabular}{l|l|}
$\square$ & FOREIGN \\
& PUBLISHIN \\
\hline
\end{tabular}

NG MEDIUM

PAPER DISKETTE (SPECIFY) OTHER (SPECIFY)

\section{SUPPLEMENTARY NOTES}

ABSTRACT (A 1500-CHARACTER OR LESS FACTUAL SUMMARY OF MOST SIONIFICANT INFORMATION. IF DOCUMENT INCLUDES A SIONIFICANT BIBLIOGRAPHY OR LITERATURE SURVEY, CITE IT HERE. SPELL OUT ACRONYMS ON FIRST REFERENCE.) (CONTINUE ON SEPARATE PAGE, IF NECESSARY.)

The purpose of this report is to describe the National Institute of Standards and Technology's work to date relating to the general methodology being developed for the project Risk Analysis for the Fire Safety of Airline Passengers and the software being used to facilitate this methodology. The approach selected involved the use of influence diagrams. Therefore, a brief discussion of influence diagrams is given. The status of their application to the water mist system for passenger planes is given and the overall approach to carrying out the project is described. An example is included that shows how the process works, but the case is fictional, not intended to be realistic.

KEY WORDS (MAXIMUM OF 9; 28 CHARACTERS AND SPACES EACH; ALPHABETIC ORDER; SEPARATE WITH SEMICOLONS; CAPITALIZE ONLY PROPER NAMES) risk analysis, risk management, probability, decision analysis, artificial intelligence, fire research

AVAILABILITY

XX UNLIMITED $\square$ FOR OFFICIAL DISTRIBUTION. DO NOT RELEASE TO NTIS. ORDER FROM SUPERINTENDENT OF DOCUMENTS, U.S. GPO, WASHINOTON, DC 20102 ORDER FROM NTIS, SPRINGFIELD, VA 22161
NOTE TO AUTHOR(S): IF YOU DO NOT WISH THIS MANUSCRIPT ANNOUNCED BEFORE PUBLICATION, PLEASE CHECK HERE. 

